\title{
Comparative Study of White and Steamed Black Panax ginseng, $P$. quinquefolium, and $P$. notoginseng on Cholinesterase Inhibitory and Antioxidative Activity
}

\author{
Mi Ra Lee, Beom Sik Yun, and Chang Keun Sung* \\ Department of Food Science and Technology, Chungnam National University, Daejeon 305-764, Korea
}

This study evaluated the anti-cholinesterases (ChEs) and antioxidant activities of white ginseng (WG) and black ginseng (BG) roots of Panax ginseng (PG), P. quinquefolium (PQ), and P. notoginseng (PN). Ginsenosides $R g_{1}, R e, R f, \mathrm{Rb}_{1}, \mathrm{Rc}_{2} \mathrm{Rb}_{2}$, and Rd were found in white PG, whereas Rf was not found in white PQ and Rf, Rc, and $\mathrm{Rb}_{2}$ were not detected in white PN. The major ginsenoside content in steamed $B G$ including $\mathrm{RK}_{3}, \mathrm{Rh}_{4}$, and $20(\mathrm{~S}) /(\mathrm{R})-\mathrm{Rg}_{3}$ was equivalent to approximately $70 \%$ of the total ginsenoside content. The WG and BG inhibited acetylcholinesteras (AChE) and butyrylcholinesterase (BChE) in a dose dependent manner. The efficacy of $\mathrm{BG}$ roots of $\mathrm{PG}, \mathrm{PQ}$, and $\mathrm{PN}$ on $\mathrm{AChE}$ and $\mathrm{BChE}$ inhibition was greater than that of the respective WG roots. The total phenolic contents and 2, 2-diphenyl-1-picryl-hydrazyl (DPPH) scavenging activity were increased by heat treatment. Among the three WG and BG, white PG and steamed black PQ have significantly higher contents of phenolic compounds. The best results for the DPPH scavenging activity were obtained with the WG and BG from PG. These results demonstrate that the steamed BG roots of the three studied ginseng species have both high ChEs inhibition capacity and antioxidant activity.

Keywords: Panax ginseng, Acetylcholinesterase, Butyrylcholinesterase, Ginseng, Antioxidants, Steamed black ginseng

\section{INTRODUCTION}

Panax ginseng (PG) has been used as a general tonic in traditional oriental medicine to increase vitality, health, and longevity, especially in elderly people [1]. Traditionally, white ginseng (WG) has been prepared from raw ginseng through an air-drying process, while red ginseng has been prepared via a steaming process at $98^{\circ} \mathrm{C}$ to $100^{\circ} \mathrm{C}$ for 2 to $3 \mathrm{~h}$. It has been reported that steamed ginseng shows enhanced pharmacological effects compared with non-steamed ginseng. Black ginseng (BG), a new ginseng product containing newly discovered ginsenosides $\left(\mathrm{Rg}_{3}, \mathrm{Rg}_{5}, \mathrm{~F} 4, \mathrm{Rg}_{6}, \mathrm{Rh}_{2}, \mathrm{Rh}_{3}, \mathrm{Rh}_{4}, \mathrm{Rk}_{3}, \mathrm{Rs}_{3}, \mathrm{Rs}\right.$, etc.) is produced by repeated steaming at high tempera-

(c) This is an Open Access article distributed under the terms of the Creative Commons Attribution Non-Commercial License (http://creativecommons.org/licenses/by-nc/3.0/) which permits unrestricted non-commercial use, distribution, and reproduction in any medium, provided the original work is properly cited. tures, upon which the product becomes black in color and exhibits more potent biological activities than white and red ginseng [2].

PG, P. quinquefolium (PQ), and P. notoginseng (PN) are the three most widely used ginseng herbs [3]. All three species of ginseng are members of the Araliacease family, and are used primarily as adaptogens. PQ is well known for its antioxidant and free radical scavenging activities [4]. PN has been reported to have beneficial effects on the heart and its constituents ginsenosides are similar to those found in PQ and PG [5]. Several reports have indicated that the medicinal efficacy of ginseng is

Received 16 Sep. 2011, Revised 25 Oct. 2011, Accepted 26 Oct. 2011

*Corresponding author

E-mail: kchsung@cnu.ac.kr

Tel: +82-42-821-6722, Fax: +82-42-822-2287 
closely linked to its protective properties against scavenging free radicals [6]. Most antioxidant potentials in herbs and spices are due to the redox properties of phenolic compounds, which allow them to act as reducing agents, hydrogen donators, and free radicals quenchers [7]. The oxidative damage that is caused by reactive oxygen species (ROS) has been frequently associated with the pathogenesis of various diseases and health problems such as aging, arthritis, cancer, inflammation, heart disease, and Alzheimer's disease (AD) [8,9].

$\mathrm{AD}$ is a brain disorder characterized by progressive and extensive decline of cognitive functions, leading to dementia due to degeneration of the cholinergic neurons in the central nervous system (CNS) [10]. Accordingly, cholinesterases (ChEs) inhibitors, which can effectively increase brain acetylcholine (ACh) levels, alleviate symptoms and delay progress, and are the most prescribed pharmacological agents in the treatment of $\mathrm{AD}$ [11]. The use of synthetic ChEs inhibitors has been limited due to their adverse side effects, including gastrointestinal disturbances and bioavailability problems [12]. A great deal of research has meanwhile been carried out on the biological effects of plants traditionally used in infusions or traditional remedies as ChEs inhibitors in vitro and also as memory enhancers in vivo [13]. Recent studies have noted that $\mathrm{AD}$ is associated with inflammatory processes where ROS are liberated [14]. Antioxidants can scavenge ROS and can also attenuate inflammatory pathways. Therefore, their use may be beneficial in the treatment of AD [15].

Although several studies have differentiated the various Panax species based on their chemical profiles and individual constituents [16], their anti-ChEs activities have yet to be compared. The present study evaluates the anti-ChEs and antioxidant activities of commercial WG and steamed BG roots of PG, PQ, and PN, as these species have not yet been studied in these respects.

\section{MATERIALS AND METHODS}

\section{Ginseng preparation}

The roots of $\mathrm{PG}$ were purchased from a local ginseng center (Geumsan, Korea). PQ and PN were kindly provided by Daeduk Bio Co. (Daejeon, Korea). To prepare $\mathrm{BG}$, commercial white $\mathrm{PG}, \mathrm{PQ}$, and $\mathrm{PN}$ roots were respectively subjected to three steps of autoclaving at $121^{\circ} \mathrm{C}$ for $30 \mathrm{~min}$ after being soaked in grape juice followed by drying at $65^{\circ} \mathrm{C}$ for $18 \mathrm{~h}$, as described by Sun [17]. To prepare the ginseng extracts, all ginsengs were crushed into powder and ultrasonicated three times in 10 volumes of $80 \%$ ethanol at $50^{\circ} \mathrm{C}$ for $1 \mathrm{~h}$, and then filtered and lyophilized.

\section{Analysis ginsenosides}

Based on a modified version of the method of Shi et al. [18], $1 \mathrm{~g}$ of dried ginseng powder was extracted three times with $50 \mathrm{~mL}$ of $80 \%$ ethanol aqueous solution at $50^{\circ} \mathrm{C}$ by ultrasonication for $1 \mathrm{~h}$. After filtration, the solvent was removed using an evaporator (Eyela NN; Tokyo Rikakiki, Tokyo, Japan), and the residue was dissolved in $20 \mathrm{~mL}$ of distilled water. The solution was transferred to a separatory funnel containing the same volume of ethyl ether. Lipid components in the sample were removed via extraction with ethyl ether three times. The sample was further extracted with $20 \mathrm{~mL}$ of water-saturated butanol layer was concentrated in vacuo. The samples were then dissolved in $10 \mathrm{~mL}$ of $80 \%$ methanol and filtered through a $0.45 \mu \mathrm{m}$ membrane filter. Saponin levels were quantified by a HPLC analysis (SPD 20A; Shimadzu, Kyoto, Japan) using an ACE $5 \mathrm{C}_{18}$ column $(250 \times 0.4 \mathrm{~mm}, 5 \mu \mathrm{m})$ and a UV detector $(203 \mathrm{~nm})$. The mobile phase was a gradient of water and acetonitrile. To elute saponin, the acetonitrile concentration was adjusted as follows: 0-30 min, 20\%; 30-60 min, 20\%-45\%; 60-78 $\min , 45 \%-75 \%$; 78-80 min, 75\%-80\%; 80-100 min, 80\%-100\%. After injecting $10 \mu \mathrm{L}$ of sample, the mobile-phase flow rate was adjusted to $1 \mathrm{~mL} / \mathrm{min}$. As controls, ginsenoside standards $\left(\mathrm{Rg}_{1}, \mathrm{Re}, \mathrm{Rf}, \mathrm{Rb}_{1}, \mathrm{Rc}, \mathrm{Rb}_{2}, \mathrm{Rd}, \mathrm{Rk}_{3}, \mathrm{Rh}_{4}, 20(\mathrm{R})\right.$ $\mathrm{Rg}_{3}, 20(\mathrm{~S})-\mathrm{Rg}_{3}$ ) with $>98 \%$ purity were purchased from Hongjiu Biotech Co., Ltd. (Jilin, China).

\section{In vitro cholinesterases inhibitory activities}

ChEs inhibitory activities were measured using the spectrophotometric method developed by Ellman et al. [19]. ACh and butyrylcholine were used as substrates to assay the inhibition of acetylcholinesterase (AChE) and butyrylcholinesterase $(\mathrm{BChE})$, respectively. The assay mixture consisted of $340 \mu \mathrm{L}$ of $0.1 \mathrm{M}$ sodium phosphate buffer ( $\mathrm{pH} 8.0$ ), $40 \mu \mathrm{L}$ of $2 \mathrm{mM} \mathrm{5,5'-dithiobis} \mathrm{(2-nitro-}$ benzoic acid) (DTNB), $40 \mu \mathrm{L}$ of the sample, and 460 $\mu \mathrm{L}$ of either $\mathrm{AChE}$ or $\mathrm{BChE}(0.22 \mathrm{U} / \mathrm{mL})$ prepared in 50 $\mathrm{mM}$ Tris buffer ( $\mathrm{pH} 8.0$ ) containing $0.1 \%$ BSA. After 10 $\mathrm{min}$, the reactions were initiated with the addition of 10 $\mu \mathrm{L}$ of either $3.75 \mathrm{mM}$ acetylthiocholine iodide (ATCI) or $3.75 \mathrm{mM}$ butyrylthiocholine chloride (BTCC) to the solution. The hydrolysis of ATCI or BTCC was monitored by observing the formation of the yellow 5-thio2-nitrobenzoate anion at $410 \mathrm{~nm}$ for $2 \mathrm{~min}$. This resulted from the reaction of DTNB with thiocholine, which was released by the enzymatic hydrolysis of either ATCI or 
BTCC, respectively. Tacrine (9-amino-1, 2, 3, 4-tetrahydroacridine hydrochloride, THA) was used as a positive control. The percent inhibition was calculated from $\left[\mathrm{A}_{0}-\right.$ $\left.A_{1} / A_{0}\right] \times 100$, where $A_{0}$ is the change in absorbance of the control and $A_{1}$ is the change in absorbance in the presence of the test compound. The ChEs inhibitory activities of each sample were expressed in terms of the $\mathrm{IC}_{50}$ value $(\mathrm{mg} / \mathrm{mL}$ required to inhibit the hydrolysis of the substrate; ATCI or BTCC, by $50 \%$ ).

\section{Total polyphenol contents}

Total polyphenol contents were determined according to Folin-Ciocalteau's method modified by Singleton and Rossi [20]. In brief, $0.2 \mathrm{~mL}$ of each ginseng extract $(10 \mathrm{mg} / \mathrm{mL})$ was mixed with $0.2 \mathrm{~mL}$ of Folin-Ciocalteau reagent, $0.4 \mathrm{~mL}$ of saturated sodium carbonate, and 3 $\mathrm{mL}$ of distilled water in a test tube. The tube was then vortexed and incubated for $1 \mathrm{~h}$. Absorbance was subsequently measured at $725 \mathrm{~nm}$. Quantification of phenol content was performed from the tannic acid calibration curve. The results were expressed as tannic acid equivalents (mg/g extract).

\section{Scavenging activity on 2, 2-diphenyl-1-picryl- hydrazyl radicals}

The stable 2, 2-diphenyl-1-picryl-hydrazyl (DPPH) radical scavenging activity was determined by Blosi's method [21]. The samples and references dissolved in ethanol were mixed with DPPH solution $\left(4 \times 10^{-4} \mathrm{M}\right)$. After $10 \mathrm{~min}$, the amount of remaining DPPH was measured at $540 \mathrm{~nm}$. Ascorbic acid was used as a positive control. Inhibition of DPPH in percent (\%) was calculated according to the following equation: DPPH scavenging activity $(\%)=\left[A_{0}-A_{1} / A_{0}\right] \times 100$, where $A_{0}$ is the absorbance of the control (containing all reagent except the test sample), and $\mathrm{A}_{1}$ is the absorbance of the test compound. $\mathrm{IC}_{50}$ is the concentration of sample needed to decrease $50 \%$ of the DPPH concentration relative to that of control.

\section{Statistical analysis}

All data were analyzed using the SPSS ver. 17.0 (SPSS Inc., Chicago, IL, USA). Ginsenoside content in two groups was analyzed by an independent samples ttest. Differences between groups were analyzed using ANOVA and Duncan's multiple range test. A difference of $p<0.05$ was regarded as being statistically significant.

\section{RESULTS AND DISCUSSION}

\section{Analysis of ginsenosides in the three white gin- seng roots}

Typical HPLC-UV chromatograms of commercial WG extracts of PG, PQ, and PN are shown in Fig. 1A to $1 \mathrm{C}$, respectively. The contents of the 11 major ginsenosides in the three species of the WG extracts are summarized in Table 1. The total ginsenoside content is $25.89 \pm 2.26 \mathrm{mg} / \mathrm{g}$ in white $P$. ginseng (WPG), $84.70 \pm 2.25$ $\mathrm{mg} / \mathrm{g}$ in white $P$. notoginseng (WPN), and $48.39 \pm 2.80$

Table 1. Ginsenoside contents in the three white and steamed black ginseng roots

\begin{tabular}{|c|c|c|c|c|c|c|}
\hline \multirow{2}{*}{ Ginsenoside } & \multicolumn{3}{|c|}{ White ginseng roots } & \multicolumn{3}{|c|}{ Steamed black ginseng roots } \\
\hline & PG & PQ & PN & PG & PQ & $\mathrm{PN}$ \\
\hline $\mathrm{Rg}_{1}$ & $4.78 \pm 0.13^{\mathrm{b}}$ & $3.13 \pm 0.26^{\mathrm{c}}$ & $34.61 \pm 0.54^{\mathrm{a}}$ & ND & ND & $2.61 \pm 0.05$ \\
\hline $\operatorname{Re}$ & $2.02 \pm 0.30^{\mathrm{c}}$ & $16.08 \pm 0.47^{\mathrm{a}}$ & $11.54 \pm 0.40^{\mathrm{b}}$ & ND & ND & $1.02 \pm 0.01$ \\
\hline $\mathrm{Rf}$ & $0.97 \pm 0.05$ & ND & ND & $0.82 \pm 0.02$ & $\mathrm{ND}$ & ND \\
\hline $\mathrm{Rb}_{1}$ & $6.80 \pm 1.23^{\mathrm{c}}$ & $22.24 \pm 1.57^{\mathrm{b}}$ & $28.93 \pm 1.04^{\mathrm{a}}$ & $4.88 \pm 0.14^{\mathrm{a}}$ & $2.07 \pm 0.30^{\mathrm{c}}$ & $3.48 \pm 0.17$ \\
\hline $\mathrm{Rc}$ & $6.70 \pm 0.14^{*}$ & $3.35 \pm 0.29$ & ND & $1.72 \pm 0.62^{\mathrm{b}}$ & $3.65 \pm 0.20^{\mathrm{a}}$ & $4.51 \pm 1.02$ \\
\hline $\mathrm{Rb}_{2}$ & $3.05 \pm 0.30^{*}$ & $0.39 \pm 0.04$ & ND & $1.76 \pm 0.34^{\mathrm{b}}$ & $1.02 \pm 0.13^{\mathrm{c}}$ & $3.53 \pm 0.37$ \\
\hline $\mathrm{Rd}$ & $1.57 \pm 0.11^{\mathrm{c}}$ & $4.75 \pm 0.16^{\mathrm{b}}$ & $9.62 \pm 0.27^{\mathrm{a}}$ & $0.52 \pm 0.04^{\mathrm{c}}$ & $0.86 \pm 0.01^{\mathrm{b}}$ & $3.02 \pm 0.19$ \\
\hline $\mathrm{Rk}_{3}$ & ND & ND & ND & $4.28 \pm 1.10^{\mathrm{b}}$ & $2.11 \pm 0.08^{\mathrm{c}}$ & $8.33 \pm 0.93$ \\
\hline $\mathrm{Rh}_{4}$ & ND & $\mathrm{ND}$ & ND & $8.84 \pm 0.85^{\mathrm{b}}$ & $3.34 \pm 0.21^{\mathrm{c}}$ & $16.15 \pm 1.10$ \\
\hline $\operatorname{Rg}_{3}(\mathrm{~S})$ & ND & ND & ND & $6.73 \pm 0.48^{\mathrm{b}}$ & $7.22 \pm 0.62^{\mathrm{b}}$ & $10.64 \pm 0.02$ \\
\hline $\mathrm{Rg}_{3}(\mathrm{R})$ & ND & ND & ND & $5.11 \pm 0.62^{\mathrm{c}}$ & $7.03 \pm 0.5^{\mathrm{b}}$ & $8.53 \pm 0.03$ \\
\hline Total & $25.89 \pm 2.26^{\mathrm{c}}$ & $48.39 \pm 2.79^{b}$ & $84.70 \pm 2.25^{\mathrm{a}}$ & $36.66 \pm 4.21^{\mathrm{b}}$ & $27.30 \pm 2.05^{\mathrm{c}}$ & $61.82 \pm 3.89$ \\
\hline
\end{tabular}

Values are expressed as means $\pm \mathrm{SD}(\mathrm{mg} / \mathrm{g}$ extract, $n=3)$. Different superscripts in the same row indicate significant differences in white ginseng and steamed black ginseng by Duncan's multiple range test. " $p<0.05$ by independent samples $t$-test.

PG, Panax ginseng; PQ, P. quinquefolium; PN, P. notoginseng; ND, not detected. 


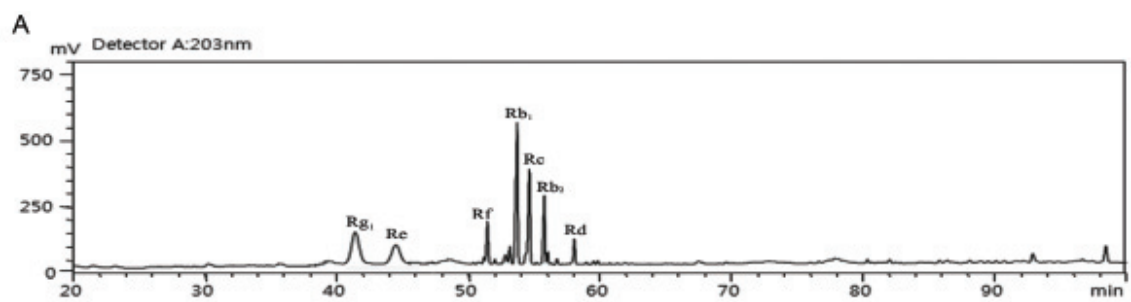

B

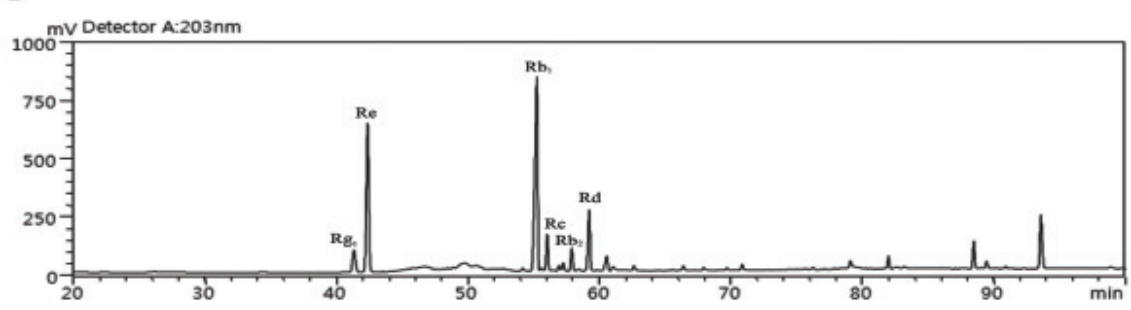

C

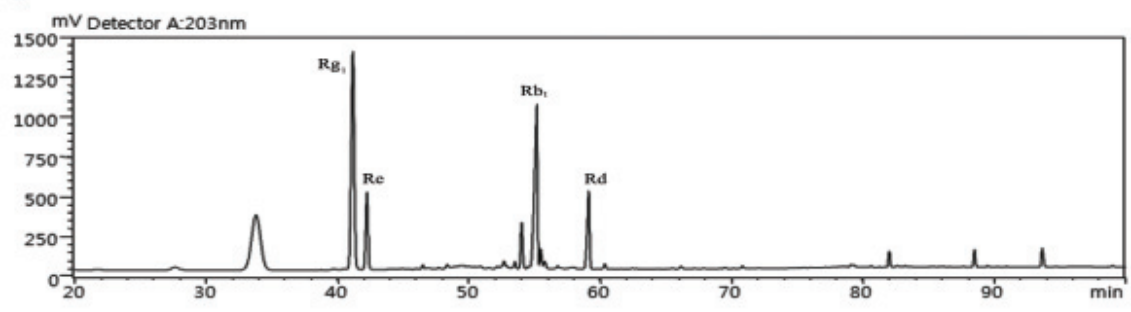

D mv Detector A:203nm

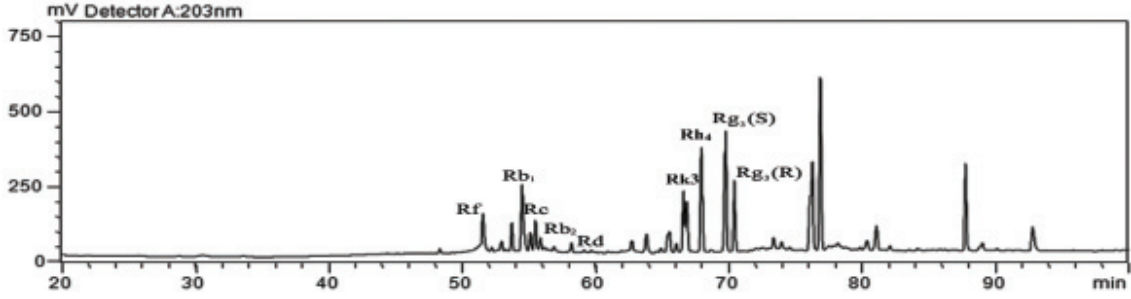

$E$
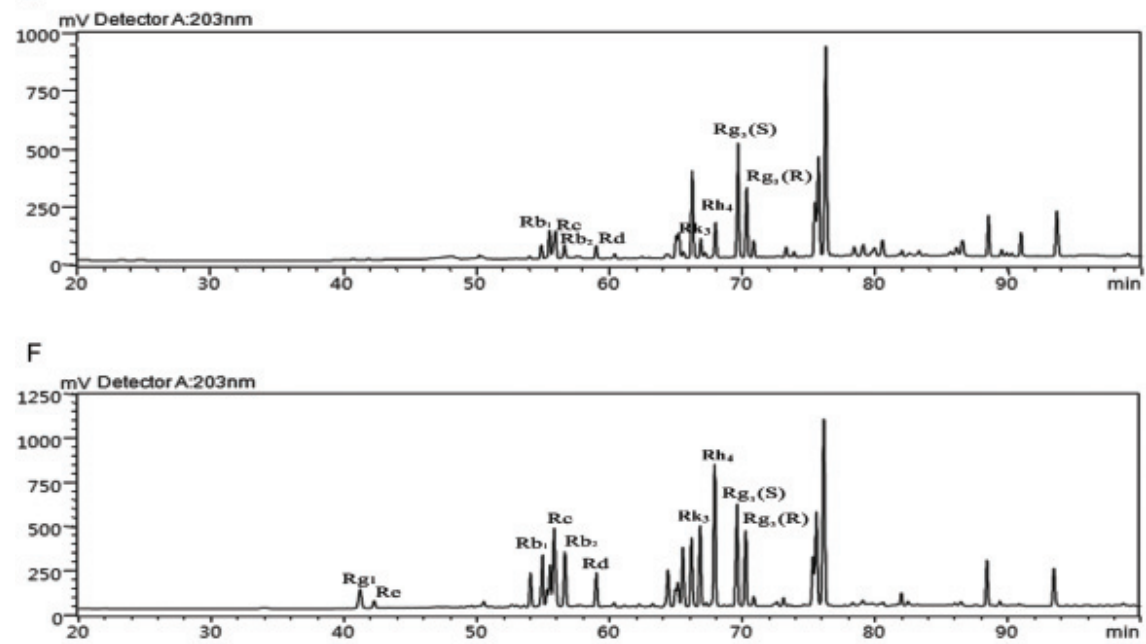

Fig. 1. HPLC-UV chromatograms of ginsenosides in (A) white Panax ginseng, (B) white $P$. quinquefolium, (C) white $P$. notoginseng, (D) steamed black $P$. ginseng, $(E)$ steamed black $P$. quinquefolium, $(F)$ steamed black $P$. notoginseng. 
$\mathrm{mg} / \mathrm{g}$ in white $P$. quinquefolium (WPQ). $\mathrm{Rg}_{1}, \mathrm{Re}, \mathrm{Rf}, \mathrm{Rb}_{1}$, $\mathrm{Rc}, \mathrm{Rb}_{2}$, and $\mathrm{Rd}$ were found in WPG, but Rf was not detected in $\mathrm{WPQ}$, and $\mathrm{Rf}, \mathrm{Rc}$ and $\mathrm{Rb}_{2}$ were not observed in WPN. Consistent with the literature, the presence of the ginsenoside $\mathrm{Rf}$ in $\mathrm{PG}$ with a content in excess of $0.1 \%$ $(\mathrm{w} / \mathrm{w})$ of the dried root was detected [22], and this is an important parameter for differentiating PG from PN and PQ. Furthermore, the content of the ginsenoside $\mathrm{Rg}_{1}$ in WPN $(34.61 \pm 0.54 \mathrm{mg} / \mathrm{g})$ was remarkably higher than that in WPG and WPQ $(4.78 \pm 0.13 \mathrm{mg} / \mathrm{g}$ and $3.13 \pm 0.26$ $\mathrm{mg} / \mathrm{g}$, respectively). WPN had the highest content of ginsenoside $\mathrm{Rb}_{1}(28.93 \pm 1.04 \mathrm{mg} / \mathrm{g})$, followed by WPQ $(22.24 \pm 1.57 \mathrm{mg} / \mathrm{g})$ and WPG $(6.80 \pm 1.23 \mathrm{mg} / \mathrm{g})$. Furthermore, the ratio of $\mathrm{Rb}_{1}$ to $\mathrm{Rg}_{1}$ might be beneficial in differentiating the three ginseng roots. $R b_{1} / R_{1}$ values between 1 and 3 are typically characteristic of $\mathrm{PG}$ and $\mathrm{PN}$, while $\mathrm{Rb}_{1} / \mathrm{Rg}_{1}$ values of 10 or more are indicative of PQ [23].

\section{Analysis of ginsenosides in the three black gin- seng roots}

Typical HPLC-UV chromatograms of steamed BG extracts of PG, PQ, and PN are shown in Fig. 1D to 1E, respectively, and the contents of the 11 major ginsenosides in the steamed BG extracts are also presented in Table 1. The total ginsenoside content in steamed black P. ginseng (BPG) was $36.66 \pm 4.21 \mathrm{mg} / \mathrm{g}$, in steamed black P. quinquefolium (BPQ), 27.30 $\pm 2.05 \mathrm{mg} / \mathrm{g}$ in BPQ, and $61.82 \pm 3.89 \mathrm{mg} / \mathrm{g}$ in steamed black $P$. notoginseng (BPN). During the steaming process, the contents of the polar ginsenosides including $\mathrm{Rg}_{1}, \mathrm{Re}, \mathrm{Rb}_{1}, \mathrm{Rc}, \mathrm{Rb}_{2}$, and $\mathrm{Rd}$ decreased remarkably, while the other ginsenosides increased. The content of the major ginsenosides in the steamed BG such as $\mathrm{RK}_{3}, \mathrm{Rh}_{4}$, and $20(\mathrm{~S}) /(\mathrm{R})-\mathrm{Rg}_{3}$ was $24.96 \pm 3.05 \mathrm{mg} / \mathrm{g}$ in BPG, $19.70 \pm 1.41 \mathrm{mg} / \mathrm{g} \mathrm{BPQ}$, and $43.65 \pm 2.08 \mathrm{mg} / \mathrm{g}$ in BPN and was equivalent to approximately $70 \%$ of the total ginsenoside content in the steamed BG. Ginsenosides $\mathrm{Rh}_{4}$ and $\mathrm{Rk}_{3}$ can be formed by deglucosylation of $\mathrm{Rg}_{6}$ and $\mathrm{F} 4$ at $\mathrm{C}-6$, while ginsenoside $\mathrm{Rg}_{3}$ can be formed by eliminating the glycosyl residue at C-20 of protopanaxdiol ginsenosides [24]. Recently, many pharmacological studies have shown that the ginsenoside $\mathrm{Rg}_{3}$ provides a neuroprotective effect against cerebral ischemia [25] and potent anti-tumor activity [26]. Therefore, production of the ginsenoside $\mathrm{Rg}_{3}$ is expected to be very important and many studies have aimed at converting major ginsenosides to the more active minor ginsenoside $\mathrm{Rg}_{3}$.

\section{Cholinesterases inhibitory activity}

The inhibitory activities on ChEs such as AChE and $\mathrm{BChE}$ of ethanol extracts of the three WG and steamed BG using PG, PQ, and PN are shown in Figs. 2 and 3. The results revealed that $\mathrm{WG}$ and $\mathrm{BG}$ inhibited both $\mathrm{AChE}$ and $\mathrm{BChE}$ in a dose dependent manner. The $\mathrm{BChE}$ inhibitory efficacy of the three WG and BG roots was higher overall than the AChE inhibition. The PG extracts of WG and $\mathrm{BG}$ were found to have the highest inhibition of AChE with estimated $\mathrm{IC}_{50}$ values of $5.37 \pm 0.20 \mathrm{mg} /$ $\mathrm{mL}$ and $2.64 \pm 0.19 \mathrm{mg} / \mathrm{mL}$, respectively (Table 2 and Fig. 2). At a concentration of $5 \mathrm{mg} / \mathrm{mL}$, the BChE inhibitory activities of the WG and $\mathrm{BG}$ for $\mathrm{PG}, \mathrm{PQ}$, and $\mathrm{PN}$ reached plateaus at $100 \%$. The WG and BG extracts of PN had the greatest inhibitory effect on $\mathrm{BChE}$ with estimated $\mathrm{IC}_{50}$ values of $1.19 \pm 0.01 \mathrm{mg} / \mathrm{mL}$ and $0.71 \pm 0.03 \mathrm{mg} / \mathrm{mL}$,
A

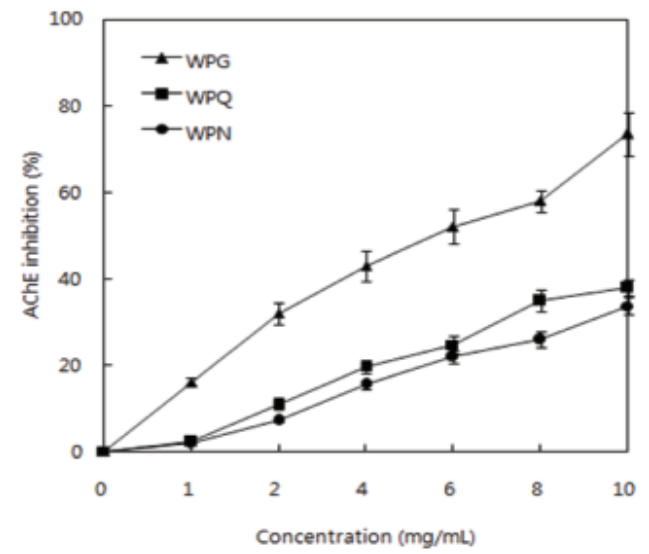

B

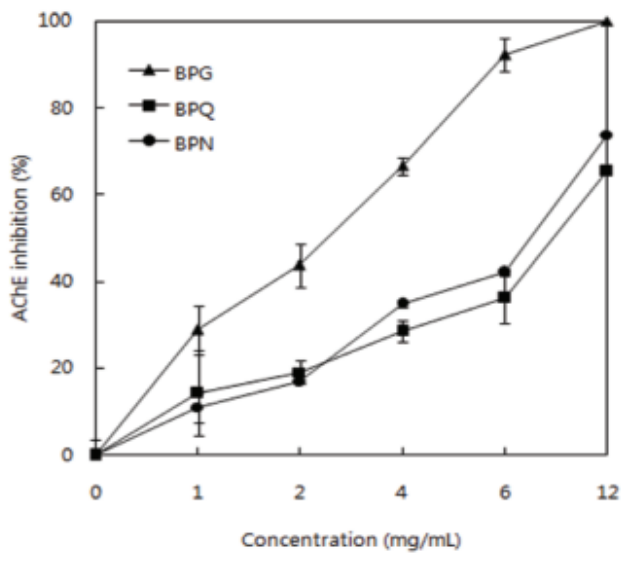

Fig. 2. Effects of the acetylcholinesterase (AChE) inhibition activities according to different concentrations of (A) white Panax ginseng (WPG), white $P$. quinquefolium (WPQ), white $P$. notoginseng (WPN), and (B) steamed black $P$. ginseng (BPG), steamed black $P$. quinquefolium (BPQ), and steamed black $P$. notoginseng (BPN). Results are expressed as means $\pm \mathrm{SD}(n=3)$. 
A

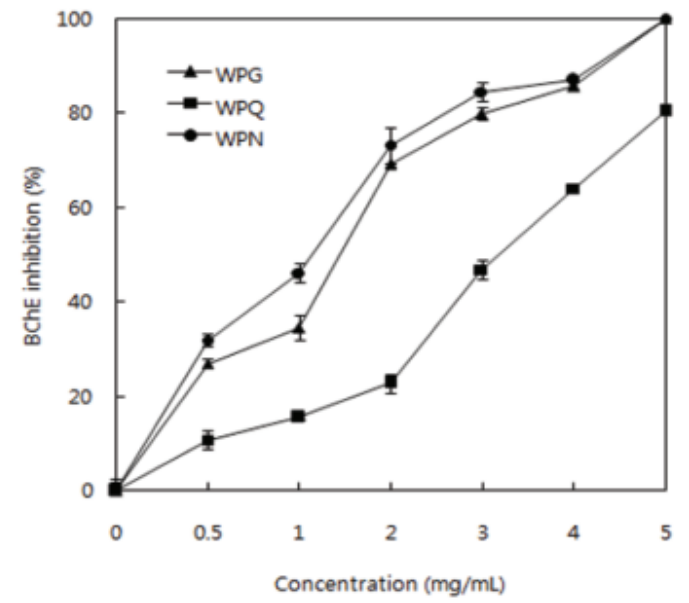

B

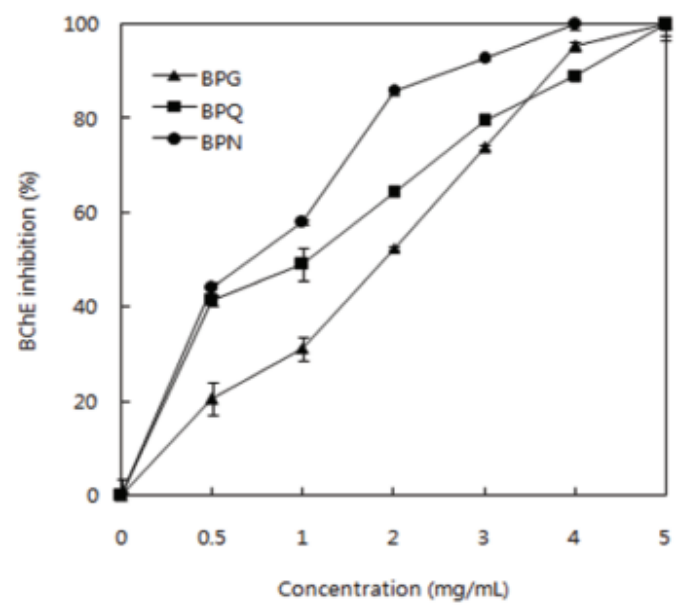

Fig. 3. Effects of the butyrylcholinesterase (BChE) inhibition activities according to the different concentrations of (A) white Panax ginseng (WPG), white $P$. quinquefolium (WPQ), white $P$. notoginseng (WPN), and (B) steamed black $P$. ginseng (BPG), steamed black $P$. quinquefolium (BPQ), and steamed black $P$. notoginseng (BPN). Results are expressed as means $\pm \mathrm{SD}(n=3)$.

A

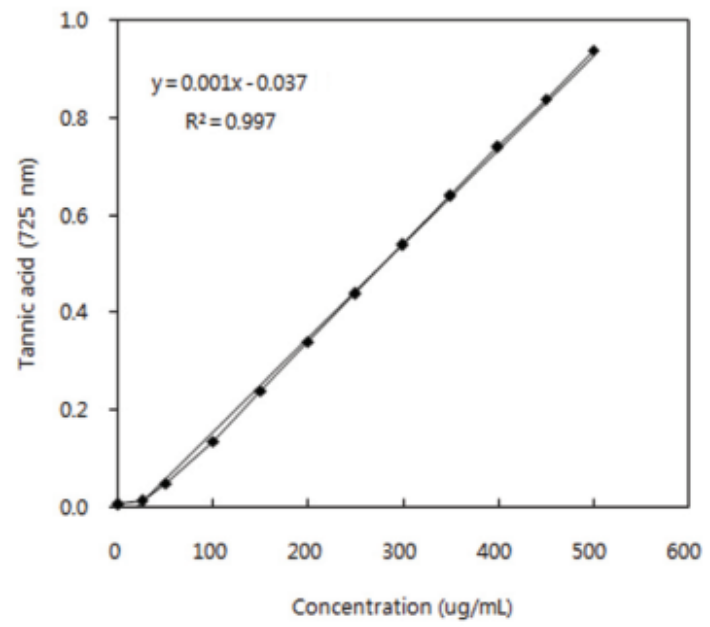

B

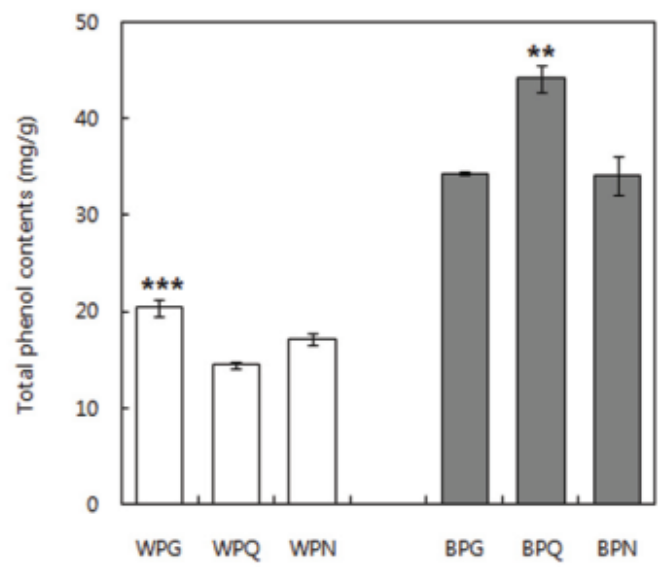

Fig. 4. The (A) standard curve of tannic acid and (B) total phenolic contents of white Panax ginseng (WPG), white P. quinquefolium (WPQ), white $P$. notoginseng (WPN), and steamed black P. ginseng (BPG), steamed black $P$. quinquefolium (BPQ), and steamed black $P$. notoginseng (BPN). Results are expressed as means \pm SD $(n=3)$.

respectively (Table 2 and Fig. 3). The $\mathrm{IC}_{50}$ values of THA (positive control) on $\mathrm{AChE}$ and $\mathrm{BChE}$ were $0.20 \pm 0.01$ $\mathrm{mg} / \mathrm{mL}$ and $0.11 \pm 0.02 \mathrm{mg} / \mathrm{mL}$, respectively.

In the human brain, both $\mathrm{AChE}$ and $\mathrm{BChE}$ are found in neurons and glia as well as in neuritic plaques and tangles in patients with $\mathrm{AD}[27]$. AChE co-localizes with $\beta$-amyloid and accelerates $\beta$-amyloid formation and deposition in $\mathrm{AD}$ [28].

The specific BChE inhibitors not only improve cognition, presumably through increased concentration of
$\mathrm{ACh}$, but also reduce levels of amyloid precursor proteins, which are a source of amyloid- $\beta$ peptides, the main component of plaques in $\mathrm{AD}$ [29]. Plant extracts, which have dual anti-ChE activity, may be appropriate for patients in moderate stages of $\mathrm{AD}$ [30]. In this screening study on the three ginseng species $\mathrm{PG}, \mathrm{PQ}$, and $\mathrm{PN}$, it was found that the extracts of $\mathrm{BG}$ for the three ginsengs were effective inhibitors of both $\mathrm{AChE}$ and $\mathrm{BChE}$. Therefore, it suggested that the ability of ginseng extracts to prevent or delay memory loss might result from their 
Table 2. $I_{50}$ values of the three white and steamed black ginseng roots on cholinesterases and antioxidant activities

\begin{tabular}{cccc}
\hline \multirow{2}{*}{ Ginseng roots } & \multicolumn{3}{c}{$\mathrm{IC}_{50}(\mathrm{mg} / \mathrm{mL})$} \\
\cline { 2 - 4 } & \multicolumn{1}{c}{$\mathrm{AChE}$} & $\mathrm{BChE}$ & \multicolumn{1}{c}{$\mathrm{DPPH}$} \\
\hline WPG & $5.37 \pm 0.20$ & $1.84 \pm 0.07$ & $4.30 \pm 0.57$ \\
WPQ & $15.01 \pm 0.75$ & $4.63 \pm 0.01$ & $11.53 \pm 0.68$ \\
WPN & $13.68 \pm 0.50$ & $1.19 \pm 0.01$ & $13.76 \pm 0.52$ \\
BPG & $2.64 \pm 0.19$ & $1.88 \pm 0.06$ & $2.11 \pm 0.20$ \\
BPQ & $8.56 \pm 0.80$ & $1.07 \pm 0.05$ & $3.53 \pm 0.31$ \\
BPN & $7.50 \pm 0.40$ & $0.71 \pm 0.03$ & $5.20 \pm 0.79$ \\
THA & $0.20 \pm 0.01$ & $0.11 \pm 0.02$ & - \\
ACA & - & - & $0.02 \pm 0.00$ \\
\hline
\end{tabular}

Values are expressed as means $\pm \mathrm{SD}(n=3)$.

AChE, acetylcholinesterase; BChE, butyrylcholinesterase; DPPH, 2, 2-diphenyl-1-picryl-hydrazyl; WPG, white Panax ginseng; WPQ, white $P$. quinquefolium; WPN, white $P$. notoginseng; BPG, steamed black $P$. ginseng; $\mathrm{BPQ}$, steamed black $P$. quinquefolium; $\mathrm{BPN}$, steamed black $P$. notoginseng; THA, tacrine; ACA, ascorbic acid.

cholinergic activity in terms of reduction of the degradation rate of ACh by inhibiting the ChEs activity.

\section{Total phenol contents}

Phenolic compounds are widely distributed in plants and are mainly produced to protect plants from stress, ROS, wounds, UV light, disease and herbivores [31]. The total phenol contents of the three WG and BG samples from $\mathrm{PG}, \mathrm{PQ}$, and PN were determined by using FolinCiocalteau's assay, calculated from the regression equation of the calibration curve $\left(y=0.002 \mathrm{x}-0.06, r^{2}=0.998\right)$ in Fig. 4A. As shown in Fig. 4B, PG has a significantly higher content of phenolic compound $(20.4 \pm 0.90 \mathrm{mg} / \mathrm{g})$, followed by PN $(17.12 \pm 0.56 \mathrm{mg} / \mathrm{g})$ and PQ $(14.45 \pm 0.13$ $\mathrm{mg} / \mathrm{g}$ ) in the WG roots. These values in the WG roots increased to $34.3 \pm 0.18,44.15 \pm 1.45$, and $34.05 \pm 2.03 \mathrm{mg} /$ $\mathrm{g}$ in the BG roots, respectively. BPQ provided the highest amount of total phenols. More than 10 phenolics in ginsengs, including ferulic, gentisic, cinnamic, syringic, and p-hydrobenzoic acids, have been reported [31]. The increase in the total phenolic contents through heat treatment is thought to be mediated by the increase of free and conjugated phenolic acid contents due to the release of bound phenolic acids linked with glucosides or amine functionalities [32]. In addition, an increase in the Maillard reaction products in ginseng as a result of heat treatment has been well documented and may be a major contributor to enhanced antioxidant activity [33].

\section{2, 2-Diphenyl-1-picryl-hydrazyl radical scavenging activity}

DPPH is a stable free radical and has been widely used to assess the ability of compounds or plant extracts to act as free radical scavenging or hydrogen donors [34]. In the DPPH scavenging activity tests of WG and BG roots from the three ginseng species, WPG and BPG scavenged $55.4 \pm 1.23 \%$ and $86.8 \pm 0.85 \%$ of the DPPH radicals, respectively, at $5 \mathrm{mg} / \mathrm{mL}$ (Fig. 5). However, at the same concentration, the scavenging activity of the WPQ (BPQ) and WPN (BPN) were only $33.02 \pm 1.04 \%$ $(65.20 \pm 1.42 \%)$ and $29.30 \pm 0.73 \%(53.31 \pm 0.57 \%)$, respectively. The DPPH scavenging activity of the BG roots increased by $1.5,1.9$, and 1.8 times relative to that of WPG, WPQ, and WPN, respectively. The $\mathrm{IC}_{50}$ values of the three ginseng extracts are shown in Table 2. The
A

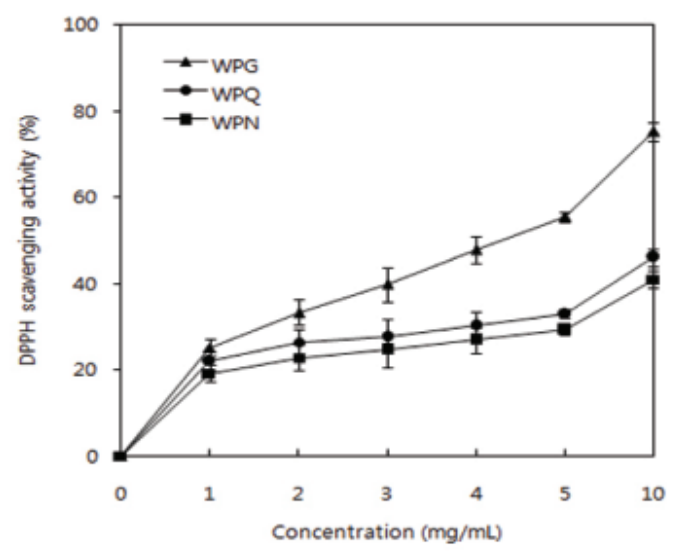

B

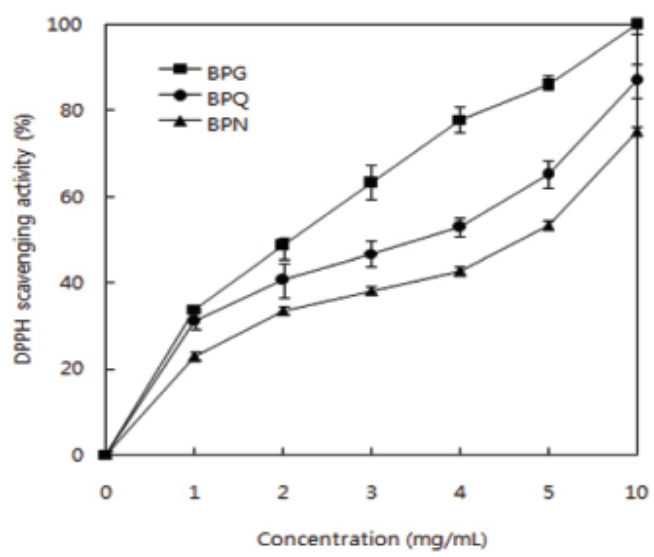

Fig. 5. Free radical 2, 2-diphenyl-1-picryl-hydrazyl (DPPH) scavenging activities of (A) white Panax ginseng (WPG), white $P$. quinquefolium (WPQ), white P. notoginseng (WPN), and (B) steamed black P. ginseng (BPG), steamed black P. quinquefolium (BPQ), and steamed black P. notoginseng (BPN). Results are expressed as Means \pm SD of triplicate determinations. 
best results for the DPPH scavenging activity were obtained with PG, BPG and WPG, with estimated $\mathrm{IC}_{50}$ values of $2.11 \pm 0.20 \mathrm{mg} / \mathrm{mL}$ and $4.30 \pm 0.57 \mathrm{mg} / \mathrm{mL}$, respectively, followed by PQ (BPQ $3.53 \pm 0.31 \mathrm{mg} / \mathrm{mL}$, WPQ $11.53 \pm 0.68 \mathrm{mg} / \mathrm{mL}$ ), and PN (BPN $5.20 \pm 0.79 \mathrm{mg} / \mathrm{mL}$, WPN $13.76 \pm 0.52 \mathrm{mg} / \mathrm{mL}$ ). The $\mathrm{IC}_{50}$ value of ACA (positive control) was $0.02 \pm 0.00 \mathrm{mg} / \mathrm{mL}$. Recently, a method to increase the content of specific ginsenoside such as $\mathrm{Rg}_{3}, \mathrm{Rg}_{5}, \mathrm{Rk}_{3}, \mathrm{Rh}_{4}$, etc. by steaming WG at higher temperature than employed for RG was developed. This novel heat processed ginseng, BG, showed enhanced free radical scavenging activity and active constituents compared to conventional ginseng [35].

\section{ACKNOWLEDGEMENTS}

This study was supported by Technology Development Program for Food, Ministry for Food, Agriculture, Forestry and Fisheries, Republic of Korea (2009-2011).

\section{REFERENCES}

1. Tang W, Eisenbrand G. Panax ginseng C. A. Meyer. In: Tang W, Eisenbrand G. Chinese drugs of plant origin: chemistry, pharmacology, and use in traditional and modern medicine. London: Springer, 1992. p.711-737.

2. Sun BS, Gu LJ, Fang ZM, Wang CY, Wang Z, Lee MR, Li Z, Li JJ, Sung CK. Simultaneous quantification of 19 ginsenosides in black ginseng developed from Panax ginseng by HPLC-ELSD. J Pharm Biomed Anal 2009;50:1522.

3. Lu GH, Zhou Q, Sun SQ, Leung KS, Zhang H, Zhao ZZ. Differentiation of Asian ginseng, American ginseng and notoginseng by Fourier transform infrared spectroscopy combined with two-dimensional correlation infrared spectroscopy. J Mol Struct 2008;883-884:91-98.

4. Kang KS, Yamabe N, Kim HY, Okamoto T, Sei Y, Yokozawa $\mathrm{T}$. Increase in the free radical scavenging activities of American ginseng by heat processing and its safety evaluation. J Ethnopharmacol 2007;113:225-232.

5. Ng TB. Pharmacological activity of sanchi ginseng (Panax notoginseng). J Pharm Pharmacol 2006;58:1007-1019.

6. Chen CY, Ribaya-Mercado JD, McKay DL, Croom E, Blumberg JB. Differential antioxidant and quinone reductase inducing activity of American, Asian, and Siberian ginseng. Food Chem 2010;119:445-451.

7. Shahidi F, Wanasundara PK. Phenolic antioxidants. Crit Rev Food Sci Nutr 1992;32:67-103.

8. Abe J, Berk BC. Reactive oxygen species as mediators of signal transduction in cardiovascular disease. Trends Car- diovasc Med 1998;8:59-64.

9. Busciglio J, Yankner BA. Apoptosis and increased generation of reactive oxygen species in Down's syndrome neurons in vitro. Nature 1995;378:776-779.

10. Cummings JL, Kaufer D. Neuropsychiatric aspects of Alzheimer's disease: the cholinergic hypothesis revisited. Neurology 1996;47:876-883.

11. Lleo A, Greenberg SM, Growdon JH. Current pharmacotherapy for Alzheimer's disease. Annu Rev Med 2006;57:513-533.

12. Melzer D. New drug treatment for Alzheimer's disease: lessons for healthcare policy. BMJ 1998;316:762-764.

13. Mukherjee PK, Kumar V, Mal M, Houghton PJ. Acetylcholinesterase inhibitors from plants. Phytomedicine 2007;14:289-300.

14. Stuchbury G, Munch G. Alzheimer's associated inflammation, potential drug targets and future therapies. J Neural Transm 2005;112:429-453.

15. Gibson GE, Huang HM. Oxidative stress in Alzheimer's disease. Neurobiol Aging 2005;26:575-578.

16. Sun S, Qi LW, Du GJ, Mehendale SR, Wang CZ, Yuan CS. Red notoginseng: higher ginsenoside content and stronger anticancer potential than Asian and American ginseng. Food Chem 2011;125:1299-1305.

17. Sun BS. Bioconversion to rare ginsenoside and memory and learning functions of white, red, and black ginsengs [dissertation]. Deajeon: Chungnam National University, 2009.

18. Shi W, Wang Y, Li J, Zhang H, Ding L. Investigation of ginsenosides in different parts and ages of Panax ginseng. Food Chem 2007;102:664-668.

19. Ellman GL, Courtney KD, Andres V Jr, Feather-Stone RM. A new and rapid colorimetric determination of acetylcholinesterase activity. Biochem Pharmacol 1961;7:8895.

20. Singleton VL, Rossi JA Jr. Colorimetry of total phenolics with phosphomolybdic-phosphotungstic acid reagents. Am J Enol Vitic 1965;16:144-158.

21. Blois MS. Antioxidant determinations by the use of a stable free radical. Nature 1958;181:1199-1200.

22. Li W, Gu C, Zhang H, Awang DV, Fitzloff JF, Fong $\mathrm{HH}$, van Breemen RB. Use of high-performance liquid chromatography-tandem mass spectrometry to distinguish Panax ginseng C. A. Meyer (Asian ginseng) and Panax quinquefolius L. (North American ginseng). Anal Chem 2000;72:5417-5422.

23. Fuzzati N. Analysis methods of ginsenosides. J Chromatogr B Analyt Technol Biomed Life Sci 2004;812:119133.

24. Cheng LQ, Na JR, Bang MH, Kim MK, Yang DC. Con- 
version of major ginsenoside $\mathrm{Rb}_{1}$ to $20(\mathrm{~S})$-ginsenoside $\mathrm{Rg}_{3}$ by Microbacterium sp. GS514. Phytochemistry 2008;69:218-224.

25. Tian J, Fu F, Geng M, Jiang Y, Yang J, Jiang W, Wang C, Liu K. Neuroprotective effect of 20(S)-ginsenoside $\mathrm{Rg}_{3}$ on cerebral ischemia in rats. Neurosci Lett 2005;374:9297.

26. Kim SM, Lee SY, Cho JS, Son SM, Choi SS, Yun YP, Yoo HS, Yoon DY, Oh KW, Han SB et al. Combination of ginsenoside $\mathrm{Rg}_{3}$ with docetaxel enhances the susceptibility of prostate cancer cells via inhibition of NF-kappaB. Eur J Pharmacol 2010;631:1-9.

27. Wright CI, Geula C, Mesulam MM. Neurological cholinesterases in the normal brain and in Alzheimer's disease: relationship to plaques, tangles, and patterns of selective vulnerability. Ann Neurol 1993;34:373-384.

28. Inestrosa NC, Alvarez A, Perez CA, Moreno RD, Vicente M, Linker C, Casanueva OI, Soto C, Garrido J. Acetylcholinesterase accelerates assembly of amyloidbeta-peptides into Alzheimer's fibrils: possible role of the peripheral site of the enzyme. Neuron 1996;16:881-891.

29. Greig NH, Utsuki T, Ingram DK, Wang Y, Pepeu G, Scali C, Yu QS, Mamczarz J, Holloway HW, Giordano T et al. Selective butyrylcholinesterase inhibition elevates brain acetylcholine, augments learning and lowers Alzheimer $\beta$-amyloid peptide in rodent. Proc Natl Acad Sci USA 2005;102:17213-17218.

30. Giacobini E. Cholinesterases: new roles in brain function and in Alzheimer's disease. Neurochem Res 2003;28:515522.

31. Dixon RA, Paiva NL. Stress-induced phenylpropanoid metabolism. Plant Cell 1995;7:1085-1097.

32. Dewanto V, Wu X, Liu RH. Processed sweet corn has higher antioxidant activity. J Agric Food Chem 2002;50: 4959-4964.

33. Lee JW, Lee SK, Do JH, Shim KH. Characteristics of the water soluble browning reaction of Korean red ginseng as affected by heating treatment. J Ginseng Res 1998;22:193-199.

34. Hatano T, Edamatsu R, Hiramatsu M, Mori A, Fujita Y, Yasuhara T, Yoshida T, Okuda T. Effects of the interaction of tannins with co-existing substances. VI. Effects of tannins and related polyphenols on superoxide anion radical, and on 1, 1-diphenyl-2-picrylhydrazyl radical. Chem Pharm Bull 1989;37:2016-2021.

35. Kim KT, Yoo KM, Lee JW, Eom SH, Hwang IK, Lee CY. Protective effect of steamed American ginseng (Panax quinquefolius L.) on V79-4 cells induced by oxidative stress. J Ethnopharmacol 2007;111:443-450. 